\title{
Effects of red pepper on appetite and energy intake
}

\author{
Mayumi Yoshioka $^{1}$, Sylvie St-Pierre ${ }^{1}$, Vicky Drapeau ${ }^{1}$, Isabelle Dionne ${ }^{1}$, Eric Doucet ${ }^{1}$, \\ Masashige Suzuki ${ }^{2}$ and Angelo Tremblay ${ }^{1 *}$ \\ ${ }^{1}$ Physical Activity Sciences Laboratory, PEPS, Laval University, Ste-Foy, Québec, Canada G1K 7P4 \\ ${ }^{2}$ Institute of Health and Sport Sciences, University of Tsukuba, Tsukuba, Ibaraki 305, Japan
}

(Received 2 July 1998 - Revised 4 January 1998 - Accepted 8 March 1999)

\begin{abstract}
Two studies were conducted to investigate the effects of red pepper (capsaicin) on feeding behaviour and energy intake. In the first study, the effects of dietary red pepper added to high-fat (HF) and high-carbohydrate (HC) meals on subsequent energy and macronutrient intakes were examined in thirteen Japanese female subjects. After the ingestion of a standardized dinner on the previous evening, the subjects ate an experimental breakfast $(1883 \mathrm{~kJ})$ of one of the following four types: (1) HF; (2) HF and red pepper (10 g); (3) HC; (4) HC and red pepper. Ad libitum energy and macronutrient intakes were measured at lunch-time. The HC breakfast significantly reduced the desire to eat and hunger after breakfast. The addition of red pepper to the $\mathrm{HC}$ breakfast also significantly decreased the desire to eat and hunger before lunch. Differences in diet composition at breakfast time did not affect energy and macronutrient intakes at lunch-time. However, the addition of red pepper to the breakfast significantly decreased protein and fat intakes at lunch-time. In Study 2, the effects of a red-pepper appetizer on subsequent energy and macronutrient intakes were examined in ten Caucasian male subjects. After ingesting a standardized breakfast, the subjects took an experimental appetizer $(644 \mathrm{~kJ})$ at lunch-time of one of the following two types: (1) mixed diet and appetizer; (2) mixed diet and red-pepper (6 $\mathrm{g}$ ) appetizer. The addition of red pepper to the appetizer significantly reduced the cumulative $a d$ libitum energy and carbohydrate intakes during the rest of the lunch and in the snack served several hours later. Moreover, the power spectral analysis of heart rate revealed that this effect of red pepper was associated with an increase in the ratio sympathetic:parasympathetic nervous system activity. These results indicate that the ingestion of red pepper decreases appetite and subsequent protein and fat intakes in Japanese females and energy intake in Caucasian males. Moreover, this effect might be related to an increase in sympathetic nervous system activity in Caucasian males.
\end{abstract}

\section{Red pepper: Appetite: Energy intake: Sympathetic nervous system activity}

Dietary fat intake has markedly increased with industrialization in many countries (Leaf \& Weber, 1987). Experimental (Lissner et al. 1987; Tremblay et al. 1989, 1991) and cross-sectional (Lissner et al. 1987; Tremblay et al. 1989, 1991) studies have demonstrated that a higher fat content in the diet is associated with an increase in daily energy intake. This is not without consequence since high fat intake seems to be associated with increased body fatness (Dreon et al. 1988; Romieu et al. 1988). Warwick \& Schiffman (1992) reviewed the literature related to the role of dietary fat in energy intake and body-weight gain in human subjects and laboratory animals. They concluded that both energy intake and expenditure are modified to favour positive energy balance when a high-fat (HF) diet is consumed and that the high energy density of HF diets plays a primary role in weight gain. This effect of HF intake on energy and lipid balance might be explained by the fact that experimental evidence supports the idea that highcarbohydrate (HC) diets are more satiating than HF diets (Thomas et al. 1992; Blundell et al. 1993; Lawton et al. 1993; Stubbs et al. 1995) and that the reduction of fat intake when fat is replaced by a fat substitute does not result in increased hunger or full compensation of decreased energy intake (Westerterp-Plantenga et al. 1997). Therefore, it could be concluded that a HF diet is characterized by a lower potency to prevent overfeeding. From a public health standpoint, the overfeeding resulting from a HF dietary regimen probably represents one of the factors responsible for the high prevalence of obesity observed in industrialized countries.

Capsaicin, which is the major pungent principle in hot red pepper, has long been used as an ingredient of spices all over 
the world. Kawada and colleagues (Kawada et al. 1986) have reported that the addition of capsaicin to a HF diet lowers perineal adipose tissue weight in rats in a dosedependent manner. We have also reported that the addition of capsaicin to a $\mathrm{HC}$ diet results in a reduction of the epididymal adipose tissue weight at the same energy intake (Matsuo et al. 1996). These results indicate that addition of capsaicin to foods could reduce adiposity, a phenomenon which can be explained partly by the enhancing effects of capsaicin on energy and lipid metabolism via catecholamine secretion from the adrenal medulla in rats (Watanabe et al. 1987a,b; Kawada et al. 1988). Since an increase in sympathetic nervous system (SNS) activity affects food intake behaviour (Russek et al. 1987; Bray, 1991; Raben et al. 1996), we hypothesized that the addition of red pepper (capsaicin) to the diet can decrease food intake and that this is associated with an increase in SNS activity. Specifically, in a first study we investigated whether the addition of red pepper to breakfasts of differing macronutrient composition could influence subsequent food intake and subjective feelings of hunger and satiety. Moreover, in order to document further the effects of red pepper on human eating behaviour, we performed a second study to investigate whether the addition of red pepper to an appetizer could influence subsequent food intake and whether this effect is related to concomitant changes in SNS activity.

\section{Methods}

Studies 1 and 2 were designed to test the impact of red pepper in real-life settings. In Study 1, we wanted to measure the impact of red pepper (capsaicin) added to meals (in this case breakfast meals) of differing macronutrient composition (HF $v$. HC) on subsequent subjective feelings of hunger and satiety as well as on subsequent ad libitum energy and macronutrient intakes at lunch-time ( $3 \mathrm{~h}$ following this test meal). Study 2 was designed to measure the impact of a preload (appetizer) with or without red pepper on ad libitum energy and macronutrient intakes immediately after consumption of this preload. Since many authors have tested similar hypotheses with a test meal given at breakfast time (see, for example, Blundell et al. 1993), we decided to adopt the same procedure. In order to be concordant with Study 1, we then had to measure ad libitum food intake after the appetizer at lunch-time. In a sense, we did not aim to reproduce the results of Study 1 with those of Study 2; rather we wanted to document further the impact of red pepper on human ad libitum food consumption. This is the main reason for the apparent differences of design between Studies 1 and 2.

\section{Study 1}

Subjects. Thirteen healthy Japanese females (age 25.8 (SD 2.8) years, weight 54.2 (SD 6.4) kg, height 1.57 (SD 0.04 ) m, body fat 25.3 (SD 4.7 ) \%) volunteered to participate in this study. The participants were asked to maintain their regular dietary habits and to abstain from intake of alcohol and caffeine on the day before the investigation. Strenuous physical activity was not allowed for $2 \mathrm{~d}$ before each experimental session to prevent the stimulation of energy metabolism (Bielinski et al. 1985; Bahr et al. 1987; Tremblay et al. 1988). All subjects were tested during the follicular phase of the menstrual cycle. The written consent of each subject was obtained before admission to the study; experimental procedures conformed to the Declaration of Helsinki.

Experimental protocol and measurements. The experimental protocol of this study was designed to investigate the effects of red pepper added to HF and HC meals on subsequent energy and macronutrient intakes. A detailed description of the composition of the red pepper used (Saemaul Kongjang 1) is given in Table 1. The subjects consumed a standardized dinner $(15,25$ and $60 \%$ energy from protein, fat and carbohydrate respectively) on the day before each session. On the next morning, they participated randomly in one of four test sessions which consisted of the measurements of energy and macronutrient intakes $3 \mathrm{~h}$ after the experimental meals, each of which provided $1883 \mathrm{~kJ}$. These meals differed between sessions according to the following specifications: HF meal (\% energy: protein 15 , fat 45 , carbohydrate 40$)$, HF and red-pepper $(10 \mathrm{~g})$ meal, HC meal (\% energy: protein 15 , fat 25 , carbohydrate 60 ), and $\mathrm{HC}$ and red-pepper meal. The subjects rested on a chair in a semi-reclining position for $3 \mathrm{~h}$ to perform calorimetric measurements after the meals. At lunch-time, the subjects were instructed to eat ad libitum in the laboratory until satiated. To facilitate the measurement of food intake, food was prepared and pre-portioned. After each meal, quantities of foods that were not entirely consumed were reweighed to determine net intake of each food. The Canadian Nutrient File 1991 software was used to calculate energy, protein, lipid and carbohydrate intakes from these measurements.

Prospective food consumption, desire to eat, hunger, fullness and satiety were measured immediately before and after the breakfast and lunch by using a $150 \mathrm{~mm}$ visual analogue scale, as further described in Table 2, which was adapted from the method previously described by Hill \& Blundell (1986). All results obtained with the

Table 1. The composition of dried hot red pepper (Data from Ku \& Choi, 1990)

\begin{tabular}{lc}
\hline Component & Content \\
\hline Crude component $(\mathrm{g} / \mathrm{kg})$ & \\
Moisture & 194 \\
Protein & 109 \\
Fat & 152 \\
Carbohydrate & 462 \\
Ash & 78 \\
Capsaicin & 3 \\
Minerals $(\mathrm{g} / \mathrm{kg})$ & \\
Calcium & 1230 \\
Phosphorus & 1400 \\
Iron & 1000 \\
Vitamins (mg/kg) & 21.1 \\
A & 3 \\
Thiamin & 2 \\
Riboflavin & 2200 \\
C & $10 \cdot 1$ \\
Metabolic energy $(\mathrm{kJ} / \mathrm{g})$ & \\
\hline
\end{tabular}


Table 2. Description of the visual analogue scale used for measurement of prospective food consumption, desire to eat, hunger, satiety and fullness

$\begin{aligned} & \text { Variable } \\ & \begin{array}{l}\text { Prospective food } \\ \text { consumption } \\ \text { Desire to eat }\end{array} \\ & \text { Hunger }\end{aligned}$
$\begin{array}{lll}\text { Satiety } \\ \text { Fullness }\end{array}$
$\begin{array}{lll}\text { Not satiated at all } \mid & \text { 4) What is your level of satiety? }\end{array}$

visual analogue scale were converted to scores ranging from 0 to 100 for statistical analysis.

Because elemental conditions and the physical state of foods affect spontaneous energy intake in human studies (Kissileff, 1985; Himaya \& Louis-Sylvestre, 1998), precautions were taken to maximize the reliability of experimental conditions: subjects were given standardized instructions, the confounding effect of external factors such as light and noise was minimal, the time interval between meals was comparable in each session, and foods used were normally eaten by subjects.

Statistical analysis. A three-way ANOVA for repeated measures was used to determine effects of diet composition, red pepper and time as well as their interactions on prospective food consumption, desire to eat, hunger, fullness and satiety. We also used a two-way ANOVA to determine the effect of diet composition $\times$ red pepper as well as the diet composition $\times$ red pepper interaction on energy and macronutrient intakes. When the ANOVA revealed a significant effect, a contrast analysis adjusting for multiple comparisons was applied to identify which conditions differed from each other. Differences were considered to be statistically significant at $P<0 \cdot 05$. Statistical analyses were performed with SuperAnova Software, version 1.11, (C) Abacus Concepts, Inc. 1991, Cary, NC, USA. All results are expressed as means with their standard errors.

\section{Study 2}

Subjects. Ten healthy Caucasian males (age 32.9 (SD 7.8) years, weight 72.5 (SD 10.1) kg, height 1.75 (SD 0.06) m) volunteered to participate in this study. The instructions to participants were the same as those in Study 1 . The written consent of each subject was obtained before admission to the study; experimental procedures conformed to the Declaration of Helsinki.

Experimental protocol and measurements. The experimental protocol of this study was designed to investigate the effects of an appetizer containing red pepper on subsequent energy and macronutrient intakes. The subjects consumed a standardized breakfast (\% energy: protein 18, fat 39 , carbohydrate 43 ) and they participated randomly in the two test sessions which consisted of measurement of ad libitum energy and macronutrient intakes after the experimental appetizers at lunch-time. In each session, the energy content of the appetizer was $644 \mathrm{~kJ}$ (\% energy: protein 15 , fat 29 , carbohydrate 56) and it differed only in red pepper content $(0 v .6 \mathrm{~g}$ red pepper). After consuming the appetizer, the subjects were instructed to eat ad libitum until satiety was reached. A snack was also offered in the middle of the afternoon ( $3 \mathrm{~h}$ after lunch) and the subjects were again instructed to eat ad libitum. The procedures to measure food intake were identical to those used in Study 1.

Heart-rate power spectral analysis was performed throughout the experiment using an electrocardiograph (Q4000 Quinton, Seattle, WA, USA). The electrocardiographic signals were digitized, stored on hard disk and sampled at a rate of $500 \mathrm{~Hz}$, with twelve precision bits. The QRS complex (lead II) was automatically recognized by a classic derivative/threshold algorithm. Power spectra were calculated from a consecutive series of 512 R-R intervals. As previously reported (Pomeranz et al. 1985; Arai et al. 1989), the ratio low-frequency $(0 \cdot 04-0 \cdot 15 \mathrm{~Hz}$ $\mathrm{Eq})$ : high-frequency $(0 \cdot 15-0 \cdot 50 \mathrm{~Hz} \mathrm{Eq})$ components of spectra was used as an indicator of the ratio sympathetic: parasympathetic nervous system activity. It has been reported that the intra-individual $\mathrm{CV}$ of heart-rate spectral analysis measured four times over $27 \mathrm{~d}$ was $16.7 \%$ (Hirsch et al. 1991). It has also been found that this method provides realistic information about changes in SNS activity in the context of experimental overfeeding and underfeeding (Aronne et al. 1995).

Statistical analysis. A two-way ANOVA for repeated measures was used to determine effects of red pepper and time as well as their interactions on dependent variables, whereas a three-way ANOVA was used to determine the effects of time, red pepper, diet composition, and their interaction on prospective food consumption, desire to eat, hunger, fullness and satiety. When the ANOVA revealed a significant effect, a contrast analysis adjusting for multiple comparisons was applied to identify which conditions differed from each other. Pearson's correlation coefficients were calculated to quantify the associations between changes in energy intake and those derived from the power spectral analysis of heart rate. Differences were considered to be statistically significant at $P<0.05$. Statistical analyses were performed with SuperAnova Software, version 1.11, (C) Abacus Concepts, Inc. 1991. 
All results are expressed as means with their standard errors.

\section{Results \\ Study 1}

Effects of red pepper added to $\mathrm{HF}$ and $\mathrm{HC}$ breakfasts on energy and macronutrient intakes are presented in Table 3. The macronutrient composition of breakfast did not affect the weight of ingested food, or energy and macronutrient intakes at lunch-time. However, the addition of red pepper to breakfast significantly decreased protein intake (by $20 \%$ and $6 \%$ for $\mathrm{HF}$ and $\mathrm{HC}$ conditions respectively, $P<0.05$ ) and fat intake (by $17 \%$ and $11 \%$ for $\mathrm{HF}$ and $\mathrm{HC}$ conditions respectively, $P<0.05)$ at lunch-time. Red pepper also tended to decrease energy intake $(11 \%$ and $4 \%$ for $\mathrm{HF}$ and $\mathrm{HC}$ conditions respectively) but this effect did not reach statistical significance.

Variations in prospective food consumption, desire to eat, hunger, fullness and satiety as measured by visual analogue scales are shown in Fig. 1. Prospective food consumption was significantly higher in the HF meal condition immediately after the breakfast and before the lunch. The addition of red pepper to experimental meals significantly decreased the prospective food consumption immediately before the lunch whereas the opposite effect was seen after the lunch. Desire to eat was significantly higher in the HF meal conditions immediately after the breakfast, but red pepper corrected this effect by significantly decreasing the desire to eat immediately after the breakfast and before the lunch. Hunger was significantly higher in the HF meal conditions immediately after the breakfast and the addition of red pepper to the experimental meals significantly decreased this variable immediately after the breakfast and before the lunch. Fullness and satiety were not significantly modified by the experimental meals.

\section{Study 2}

The effects of the red-pepper appetizer on energy and macronutrient intakes are shown in Table 4; these values do not include the energy and macronutrient content of the appetizer. The addition of red pepper to the experimental appetizer significantly decreased cumulative (lunch + mid-afternoon snack) carbohydrate intake $(18 \%, P<0.05)$ and energy intake $(11 \%, P<0.05)$ at lunch and snack.
Fig. 2 presents changes in the sympathetic:parasympathetic nervous system activity ratio as reflected by changes in the low: high frequency ratio of the power spectra as measured by power spectral analysis of heart rate. The addition of red pepper to the experimental appetizer significantly increased the sympathetic : parasympathetic nervous system activity ratio during and immediately after the appetizer ingestion. However, there was no further effect of the red pepper appetizer during or after the ad libitum lunch.

The correlation between changes in the sympathetic: parasympathetic nervous system activity ratio from baseline and energy intake is shown in Fig 3. Changes in the sympathetic: parasympathetic nervous system activity ratio tended to be negatively correlated with energy intake, but this effect failed to reach standard statistical significance $(P=0 \cdot 09)$.

In the two studies, no subject reported nausea or any other unpleasant effects related to red pepper ingestion. Although this issue was not investigated with specific questions, the absence of unpleasant sensations related to red-pepper ingestion suggests that its effects were not explained by a transitory discomfort under the red-pepper condition.

\section{Discussion}

The results of these studies indicate that the ingestion of red pepper decreases subsequent protein and fat intakes as well as appetite in Japanese females. In Caucasian males, redpepper ingestion reduces spontaneous energy intake, an effect which might be related to an increase in SNS activity. Addition of capsaicin to the diet is known to affect energy metabolism by activating the SNS in animals (Watanabe et al. 1987a,b; Kawada et al. 1988), and an increase in SNS activity is known to favour a decrease in food intake (Russek et al. 1987; Bray, 1991; Raben et al. 1996). In the present study, we investigated the effects of dietary red pepper on energy and macronutrient intakes. The impact of diet composition on feeding behaviour and subsequent energy intake was also examined.

\section{Effect of diet composition on food intake behaviour}

In Study 1, the desire to eat and the level of hunger immediately after the $\mathrm{HF}$ breakfast were greater than those observed after the HC breakfast. The prospective food consumption was also greater immediately after the

Table 3. Study 1. Energy and macronutrient intakes at lunch-time after the ingestion of a high-fat $(\mathrm{HF})$, $H F$ red-pepper (HF+RP), high-carbohydrate $(\mathrm{HC})$ or $\mathrm{HC}$ red-pepper $(\mathrm{HC}+\mathrm{RP})$ breakfast $^{*}$

(Mean values and standard deviations for thirteen subjects)

\begin{tabular}{|c|c|c|c|c|c|c|c|c|c|}
\hline \multirow[t]{2}{*}{ Breakfast ... } & \multicolumn{2}{|c|}{ HF } & \multicolumn{2}{|c|}{$H F+R P$} & \multicolumn{2}{|c|}{$\mathrm{HC}$} & \multicolumn{2}{|c|}{$\mathrm{HC}+\mathrm{RP}$} & \multirow{2}{*}{$\begin{array}{c}\text { Significant } \\
\text { effect } †\end{array}$} \\
\hline & Mean & SD & Mean & SD & Mean & SD & Mean & SD & \\
\hline Food intake (g) & 786 & 66 & 702 & 76 & 768 & 67 & 738 & 80 & \\
\hline Protein intake (g) & 28.6 & $3 \cdot 7$ & 22.9 & 3.5 & $28 \cdot 3$ & 4.0 & $26 \cdot 6$ & $4 \cdot 3$ & $\mathrm{RP}$ \\
\hline Fat intake $(\mathrm{g})$ & $29 \cdot 6$ & $3 \cdot 1$ & 24.7 & $3 \cdot 0$ & $29 \cdot 2$ & $3 \cdot 3$ & $26 \cdot 1$ & 3.4 & $\mathrm{RP}$ \\
\hline Carbohydrate intake (g) & $104 \cdot 3$ & $13 \cdot 5$ & $100 \cdot 0$ & $13 \cdot 2$ & $101 \cdot 8$ & $12 \cdot 6$ & $103 \cdot 3$ & 11.9 & \\
\hline Energy intake (kJ) & 3340 & 381 & 2988 & 352 & 3281 & 368 & 3155 & 356 & \\
\hline
\end{tabular}

* For details of meals and procedures, see pp. 116-117.

$\dagger$ Significant effect determined by two-way ANOVA, $P<0.05$. There was no significant diet $\times$ RP interaction. 

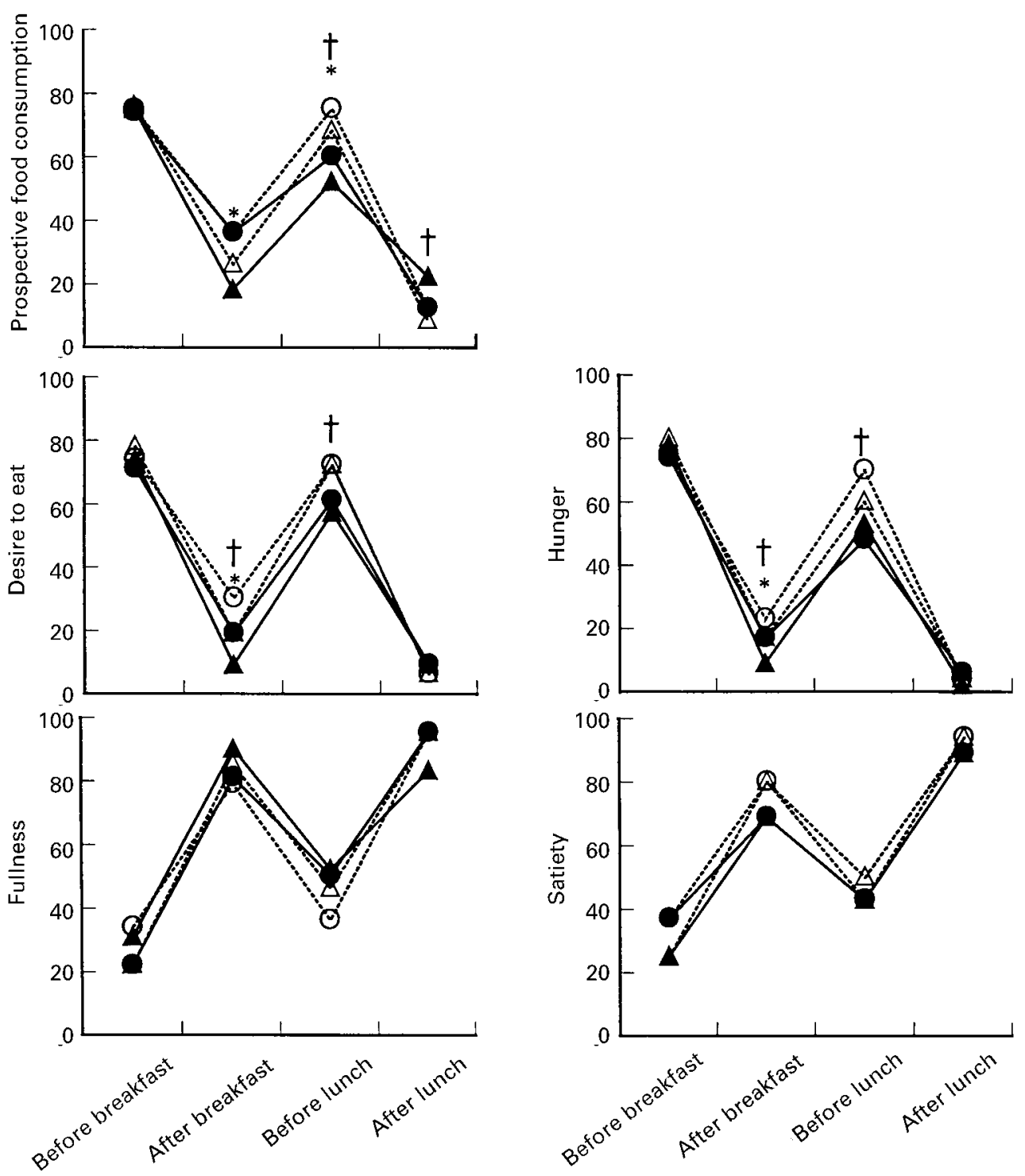

Fig. 1. Study 1. Values for prospective food consumption, desire to eat, hunger, fullness and satiety, measured by a visual analogue scale (Table 2), immediately before and after high-fat and high-carbohydrate breakfasts with or without red pepper, and before and after a subsequent

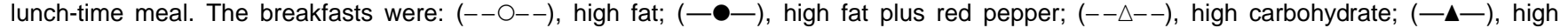
carbohydrate plus red pepper. Values are means for thirteen subjects. There was a significant effect of diet composition by three-way ANOVA, ${ }^{*} P<0.05$, and a significant effect of red pepper by three-way ANOVA, $\dagger P<0.05$.

Table 4. Study 2. Energy and macronutrient intakes at lunch-time and snack time after the ingestion of a control or red-pepper (RP) appetizer* (Mean values and standard deviations for ten subjects)

\begin{tabular}{|c|c|c|c|c|c|c|c|c|c|}
\hline & \multicolumn{4}{|c|}{ Control appetizer } & \multicolumn{4}{|c|}{ Red-pepper appetizer } & \multirow{3}{*}{$\begin{array}{c}\text { Significant } \\
\text { effect† }\end{array}$} \\
\hline & \multicolumn{2}{|c|}{ Lunch } & \multicolumn{2}{|c|}{ Snack } & \multicolumn{2}{|c|}{ Lunch } & \multicolumn{2}{|c|}{ Snack } & \\
\hline & Mean & SD & Mean & SD & Mean & SD & Mean & SD & \\
\hline Food intake $(\mathrm{g})$ & 979 & 94 & 373 & 94 & 943 & 70 & 290 & 73 & $\mathrm{~T}$ \\
\hline Protein intake $(\mathrm{g})$ & $52 \cdot 8$ & $7 \cdot 2$ & $7 \cdot 1$ & 1.9 & $46 \cdot 7$ & $6 \cdot 7$ & $8 \cdot 3$ & 2.5 & $\mathrm{~T}$ \\
\hline Fat intake $(\mathrm{g})$ & $65 \cdot 6$ & 3.2 & 13.4 & 3.2 & $62 \cdot 3$ & $6 \cdot 7$ & $13 \cdot 7$ & 3.9 & $\mathrm{~T}$ \\
\hline Carbohydrate intake (g) & 133.5 & $10 \cdot 5$ & $60 \cdot 8$ & 13.5 & $112 \cdot 8$ & $9 \cdot 8$ & $45 \cdot 8$ & $12 \cdot 0$ & $\mathrm{~T}, \mathrm{RP}$ \\
\hline Energy intake (kJ) & 5583 & 598 & 1645 & 343 & 5018 & 456 & 1419 & 372 & $\mathrm{~T}, \mathrm{RP}$ \\
\hline
\end{tabular}

\section{T, time.}

${ }^{*}$ For details of meals and procedures, see pp. 116-118.

$\dagger$ Significant effect determined by two-way ANOVA, $P<0.05$. There was no significant $\mathrm{T} \times \mathrm{RP}$ interaction. 


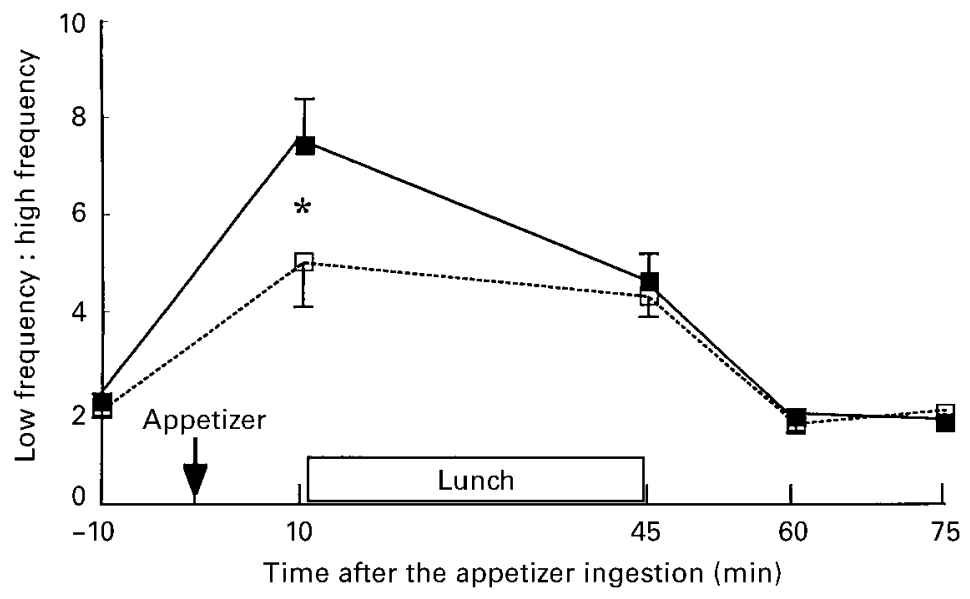

Fig. 2. Study 2. Values for the sympathetic: parasympathetic nervous system activity ratio (expressed as the low : high frequency ratio of the power spectra as measured by power spectral analysis of heart rate) before and after ingestion of a control appetizer $(--\square--)$ and an appetizer containing red pepper (-- - - ). Values are means for ten subjects, with their standard errors represented by vertical bars. There was a significant effect of red pepper determined by two-way ANOVA, ${ }^{*} P<0.05$.

HF breakfast and before the lunch than for the HC breakfast condition. These results are in agreement with those of previous studies which demonstrated that HF foods have a weak potential to promote satiety acutely (Blundell et al. 1993; Lawton et al. 1993). However, the present results show that these changes were not associated with significant changes in ad libitum food and energy intakes at lunch-time. The lack of a statistically significant difference in energy intake might be due to the absence of a change in carbohydrate intake but may also be attributable to a type 2 error caused by a lack of statistical power due to the large between-subject variation in the response to the ingestion of red pepper.

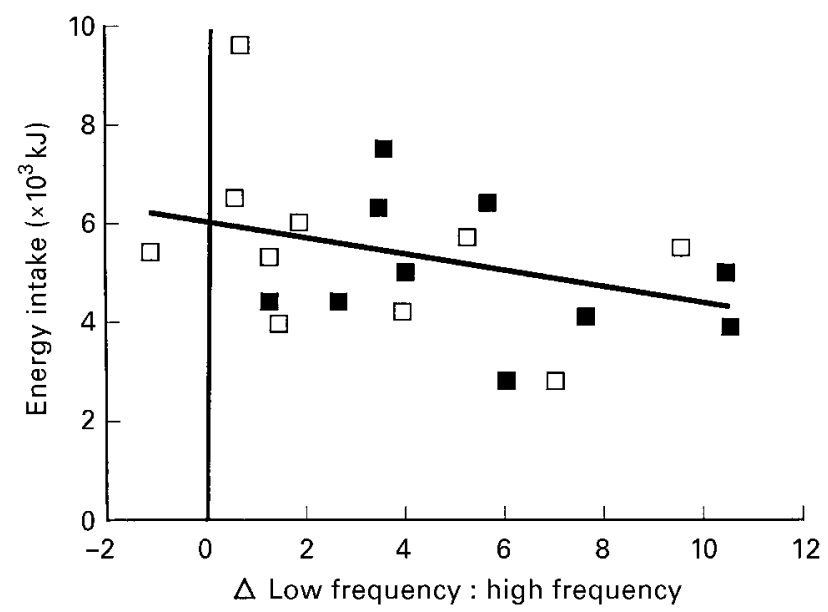

Fig. 3. Study 2. Correlation between changes in the sympathetic: parasympathetic nervous system activity ratio (expressed as the low: high frequency ratio of the power spectra as measured by power spectral analysis of heart rate) and energy intake at lunchtime and snack meals in subjects consuming a control appetizer $(\square)$ or an appetizer containing red pepper $(\boldsymbol{\square})$. Values were obtained in ten subjects who participated in two testing sessions. The relationship is described by the equation: $Y=-184.7 X+6070(P=0.0895, r-0.390)$.

\section{Effect of red pepper on food intake behaviour}

It is generally believed that red pepper is used for increasing appetite under conditions of high temperature and humidity during summer time in Japan. However, experimental evidence suggests that capsaicin has the potential to decrease food intake in animals, an effect that might be mediated by SNS activity (Watanabe et al. 1987a,b; Kawada et al. 1988). The addition of red pepper to breakfast significantly decreased protein and fat intakes at lunchtime in Study 1, and the red-pepper appetizer decreased carbohydrate and energy intakes in Study 2. Moreover, these changes in macronutrient intake were accompanied by changes in appetite such as decreased prospective food consumption, desire to eat and hunger in Study 1. This difference between popular belief and experimental data may be explained in part by the amount of the spice ingested. Indeed, high doses of capsaicin were used in the injection studies with rats (Watanabe et al. 1987a,b; Kawada et al. 1988) and in the studies where oral administration of capsaicin or red pepper was performed in rats or human subjects (Kawada et al. 1986; Yoshioka et al. 1995; Matsuo et al. 1996; Lim et al. 1997) compared with the habitual consumption in Japan. Therefore there is a possibility that a small to moderate level of red pepper in the diet might increase food intake. Since the number of papers which document the effects of red pepper in human subjects is quite limited, further research would be needed to clarify the effects of different doses of red pepper on food and/or energy intake.

\section{Relationship between sympathetic nervous system activity and food intake behaviour}

Bray (1993) has proposed that SNS activity affects food intake. Moreover, Raben et al. (1996) have recently demonstrated an association between postprandial noradrenaline 
release and the appetite scores. Therefore, these observations imply that increasing SNS activity should result in a decrease in ad libitum food intake. In Study 2, the addition of red pepper to the experimental appetizer significantly decreased energy intake at lunch-time and significantly increased the sympathetic: parasympathetic nervous system activity ratio during and immediately after ingestion of the appetizer. Moreover, $\Delta$ sympathetic: parasympathetic nervous system activity ratio tended to be negatively correlated with energy intake. If we postulate that this change in the sympathetic: parasympathetic nervous system activity ratio reflects an increase in SNS activity, these results are in agreement with those of Russek et al. (1987) who demonstrated that catecholamines, especially adrenaline, have an anorectic effect that may be due to a modification of the hepatic metabolism. We have recently reported that there is a peak increase in catecholamine levels immediately after red-pepper ingestion (Lim et al. 1997) and that the increase in thermogenesis immediately after the ingestion of red pepper is abolished by a $\beta$-adrenergic blockade (Yoshioka et al. 1995). Thus, these changes in catecholamines might have also affected the feeding behaviour in the present studies. The latter observations suggest that spicy foods taken as an appetizer could be a successful prescription to decrease subsequent ad libitum energy intake and to increase thermogenesis, because spices such as red pepper increase SNS activity.

In summary, the addition of red pepper to a meal decreased the desire to eat as well as protein and fat intakes at the next meal in Japanese subjects. Moreover, the addition of red pepper to an appetizer at lunch-time decreased carbohydrate and energy intakes at lunch and snack meals in Caucasians. These changes in energy intake tended to be negatively correlated with the increase in the sympathetic: parasympathetic nervous system activity ratio as measured by power spectral analysis of heart rate. These results suggest that the addition of red pepper to the diet decreases energy intake, an effect which might be mediated by an increase in SNS activity.

\section{Acknowledgement}

This study was supported by the Natural Sciences and Engineering Research Council of Canada.

\section{References}

Arai Y, Saul P, Albrecht P, Hartley LH, Lilly LS, Cohen RJ \& Colucci WS (1989) Modulation of cardiac autonomic activity during and immediately after exercise. American Journal of Physiology 256, H132-H141.

Aronne LJ, Mackintosh R, Rosenbaum M, Leibel RL \& Hirsch J (1995) Autonomic nervous system activity in weight gain and weight loss. American Journal of Physiology 269, R222-R225.

Bahr R, Ingnes I, Vaage O, Sejersted OM \& Newsholme EA (1987) Effect of duration of exercise on excess postexercise $\mathrm{O}_{2}$ consumption. Journal of Applied Physiology 62, 485-490.

Bielinski R, Schutz Y \& Jéquier E (1985) Energy metabolism during the postexercise recovery in man. American Journal of Clinical Nutrition 42, 69-82.

Blundell J, Burley VJ, Cotton JR \& Lawton CL (1993) Dietary fat and control of energy intake: evaluating the effects of fat on meal size and postmeal satiety. American Journal of Clinical Nutrition 57, 772S-778S.

Bray G (1991) A disorder of nutrient partitioning: MONA LISA hypothesis. Journal of Nutrition 121, 1146-1162.

Bray GA (1993) Food intake, sympathetic activity, and adrenal steroids. Brain Research Bulletin 32, 537-541.

Dreon DM, Frey-Hewitt B, Ellsworth N, Williams PT, Terry RB and Wood PD (1988) Dietary fat:carbohydrate ratio and obesity in middle-aged men. American Journal of Clinical Nutrition 47, 995-1000.

Hill AJ \& Blundell JE (1986) The effects of a high-protein or highcarbohydrate meal on subjective motivation to eat and food preferences. Nutrition and Behavior 3, 133-144.

Himaya A \& Louis-Sylvestre J (1998) The effect of soup on satiation. Appetite 30, 199-210.

Hirsch J, Leibel RL, Mackintish R \& Aguirre A (1991) Heart rate variability as a measure of autonomic function during weight change in humans. American Journal of Physiology 261, R1418-R1423.

Kawada T, Hagihara K-I \& Iwai K (1986) Effects of capsaicin on lipid metabolism in rats fed high fat diet. Journal of Nutrition 116, 1272-1278.

Kawada T, Sakabe S, Watanabe T, Yamamoto M \& Iwai K (1988) Some pungent principles of spices cause the adrenal medulla to secrete catecholamine in anesthesized rats. Proceedings of the Society for Experimental Biology and Medicine 188, 229233.

Ku Y \& Choi S (1990) The composition of foods. In The Scientific Technology of Kimchi, pp. 33-34 [Korean Institute of Food Development, editors]. Seoul, Korea: Korean Institute of Food Development.

Kissileff HR (1985) Effects of physical state (solid-liquid) of foods on food intake: procedural and substantive contributions. American Journal of Clinical Nutrition 42, 956-965.

Lawton CL, Burley VJ, Wales JK \& Blundell JE (1993) Dietary fat and appetite control in obese subjects: weak effects on satiety. International Journal of Obesity 17, 409-416.

Leaf A \& Weber PC (1987) A new era for science in nutrition. American Journal of Clinical Nutrition 45, 1048-1053.

Lim K, Yoshioka M, Kikuzato S, Kiyonaga A, Tanaka H, Shindo M \& Suzuki M (1997) Dietary red pepper ingestion increased carbohydrate oxidation at rest and during exercise in runners. Medicine and Science in Sports and Exercise 29, 355-361.

Lissner L, Levitsky DA, Strupp BJ, Kalkwarf HJ \& Roe DA (1987) Dietary fat and regulation of energy intake in human subjects. American Journal of Clinical Nutrition 46, 886-892.

Matsuo T, Yoshioka M \& Suzuki M (1996) Capsaicin in diet does not affect glycogen contents in the liver and skeletal muscle of rats before and after exercise. Journal of Nutritional Science and Vitaminology 42, 249-256.

Pomeranz B, Macaulay RJB, Caudill MA, Kutz I, Adam D, Gordon D, Kilborn KM, Barger AC, Shannon DC, Cohen RJ \& Benson H (1985) Assessment of autonomic function in humans by heart rate spectral analysis. American Journal of Physiology 248, H151-H153.

Raben A, Holst JJ, Christensen NJ \& Astrup A (1996) Determinants of postprandial appetite sensations: macronutrient intake and glucose metabolism. International Journal of Obesity 20, 161-169.

Romieu I, Willett WC, Stampfer MJ, Colditz GA, Sampson L, Rosner B, Hennekens CH \& Speizer FE (1988) Energy intake and other determinants of relative weight. American Journal of Clinical Nutrition 47, 406-412.

Russek M, Vega C, Berrera J, Soto-Mora LM, Langazorta A \& Racotta R (1987) Anorexia elicited by different catecholamines in rats. Appetite 9, 119-126.

Stubbs RJ, Harbron CH, Murgatroyd PR \& Prentice AM (1995) 
Covert manipulation of dietary fat and energy density: effect on substrate flux and food intake in men eating ad libitum. American Journal of Clinical Nutrition 62, 316-329.

Thomas CD, Peters JC, Reed GW, Abumrad NN, Sun M \& Hill JO (1992) Nutrient balance and energy expenditure during ad libitum feeding of high-fat and high-carbohydrate diets in humans. American Journal of Clinical Nutrition 55, 934-942.

Tremblay A, Lavallée N, Alméras N, Allard L, Després JP \& Bouchard C (1991) Nutritional determinants of the increase in energy intake associated with a high fat diet. American Journal of Clinical Nutrition 53, 1134-1137.

Tremblay A, Nadeau A, Fournier G \& Bouchard C (1988) Effect of a three-day interruption of exercise training on resting metabolic rate and glucose-induced thermogenesis in trained individuals. International Journal of Obesity 12, 163-168.

Tremblay A, Plourde G, Després JP \& Bouchard C (1989) Impact of dietary fat content and fat oxidation on energy intake in humans. American Journal of Clinical Nutrition 49, 799-805.

Warwick ZS \& Schiffman SS (1992) Role of dietary fat in calorie intake and weight gain. Neuroscience and Biobehavioral Reviews 16, 585-596.

Watanabe T, Kawada T \& Iwai K (1987a) Enhancement by capsaicin of energy metabolism in rats through secretion of catecholamine from adrenal medulla. Agricultural and Biological and Chemistry 51, 75-79.

Watanabe T, Kawada T, Yamamoto M \& Iwai K (1987b) Capsaicin, a pungent principle of hot red pepper, evokes catecholamine secretion from the adrenal medulla of anesthetized rats. Biochemical and Biophysical Research Communications 142, 259-264.

Westerterp-Plantenga MS, Wijckmans-Duijsens NE, ten Hoor F \& Weststrate JA (1997) Effect of replacement of fat by nonabsorbable fat (sucrose polyester) in meals or snacks as a function of dietary restraint. Physiology and Behavior 61, 939-947.

Yoshioka M, Lim K, Kikuzato S, Kiyonnaga A, Tanaka H, Shindo M \& Suzuki M (1995) Effects of red-pepper diet on the energy metabolism in men. Journal of Nutritional Science and Vitaminology 41, 647-656.

(C) Nutrition Society 1999

\section{Appendix}

Study 1

Table 1. Compositions of the high-fat and high-carbohydrate breakfast meals

\begin{tabular}{|c|c|c|c|c|c|}
\hline Food & Weight (g) & Energy (kJ) & Protein $(\mathrm{g})$ & Fat $(\mathrm{g})$ & Carbohydrate (g) \\
\hline \multicolumn{6}{|l|}{ High-fat breakfast } \\
\hline Scallops & $26 \cdot 4$ & $107 \cdot 1$ & $5 \cdot 3$ & 0.3 & 0.5 \\
\hline Green peppers & $43 \cdot 3$ & 51.9 & 0.0 & $0 \cdot 1$ & $2 \cdot 8$ \\
\hline Onions & 41.0 & 62.8 & 0.0 & 0.1 & 3.5 \\
\hline Tomatoes & $42 \cdot 3$ & 38.9 & 0.0 & 0.1 & $2 \cdot 0$ \\
\hline Shrimps & $20 \cdot 1$ & 94.6 & 4.4 & 0.4 & 0.2 \\
\hline Rice (cooked) & $126 \cdot 8$ & 663.6 & 3.0 & 0.4 & $35 \cdot 8$ \\
\hline Bacon & 37.0 & 698.7 & $4 \cdot 1$ & $16 \cdot 6$ & 0.3 \\
\hline Oil & 4.4 & $165 \cdot 7$ & 0.0 & 4.4 & 0.0 \\
\hline Total: $\mathrm{g}$ & 341.3 & & $16 \cdot 9$ & 22.5 & 45.1 \\
\hline kJ & & $1883 \cdot 2$ & 282.0 & 846.5 & 754.7 \\
\hline (kcal) & & $(450 \cdot 1)$ & $(67.4)$ & $(202 \cdot 3)$ & $(180 \cdot 4)$ \\
\hline$\%$ energy & & & $15 \cdot 0$ & 44.9 & 40.1 \\
\hline \multicolumn{6}{|c|}{ High-carbohydrate breakfast } \\
\hline Scallops & $10 \cdot 0$ & $40 \cdot 6$ & $2 \cdot 0$ & 0.1 & 0.2 \\
\hline Green peppers & $37 \cdot 0$ & 44.4 & 0.0 & 0.1 & $2 \cdot 4$ \\
\hline Onions & 34.0 & $52 \cdot 3$ & 0.0 & 0.1 & $2 \cdot 9$ \\
\hline Tomatoes & 65.5 & 59.8 & 0.0 & 0.2 & $3 \cdot 1$ \\
\hline Shrimps & 38.0 & 178.2 & 8.4 & 0.8 & 0.4 \\
\hline Rice (cooked) & 206.5 & $1080 \cdot 7$ & $5 \cdot 0$ & 0.6 & 58.2 \\
\hline Bacon & 14.2 & 268.2 & 1.6 & $6 \cdot 4$ & 0.1 \\
\hline Oil & 4.2 & $158 \cdot 2$ & 0.0 & 4.2 & 0.0 \\
\hline \multirow{4}{*}{$\begin{array}{l}\text { (Kcal) } \\
\% \text { energy }\end{array}$} & $409 \cdot 4$ & & $16 \cdot 9$ & $12 . \overline{5}$ & 67.4 \\
\hline & & $1882 \cdot 8$ & $282 \cdot 7$ & $472 \cdot 2$ & $1127 \cdot 8$ \\
\hline & & $(450 \cdot 0)$ & $(67.6)$ & $(112.9)$ & $(269.6)$ \\
\hline & & & $15 \cdot 0$ & $25 \cdot 1^{\prime}$ & 59.9 \\
\hline
\end{tabular}

Table 2. List of foods served (in large amounts) during the lunch-time buffet

\begin{tabular}{lll}
\hline Cola & Red apples & Cucumber \\
7-up ${ }^{\circledR}$ & Bananas & Lettuce \\
Apple juice & Oranges & Tomatoes \\
Orange juice & White bread & Sliced ham \\
Milk (3.5\% fat) & Muffins & Brie cheese \\
Tea & Melba ${ }^{\circledR}$ toasts & Turkey \\
Oreo ${ }^{\circledR}$ cookies & White rice & Salami \\
Tea biscuits & Celery & Fish \\
Fruit yoghurt & Carrots & Nori (Japanese food) \\
Ketchup & Soya sauce & Chazuke (Japanese food) \\
Mustard & Butter & \\
\hline
\end{tabular}


Study 2

Table 3. Compositions of the red-pepper and control appetizers

\begin{tabular}{lcccc}
\hline Food & Weight $(\mathrm{g})$ & Protein $(\mathrm{g})$ & Fat $(\mathrm{g})$ & Carbohydrate $(\mathrm{g})$ \\
\hline Red-pepper appetizer & & & & \\
White bread & 18 & 1.51 & 0.68 & 8.64 \\
Tomatoes & 10 & 0.07 & 0.01 & 0.33 \\
Pimentoes & 5 & 0.05 & 0.01 & 0.21 \\
Cream cheese (regular) & 8 & 0.85 & 1.33 & 0.32 \\
Red pepper & 3 & 0.33 & 0.46 & 1.39 \\
Total: g & 44.0 & 2.8 & 2.5 & 10.9 \\
kJ & 323.0 & 46.9 & 93.7 & 182.4 \\
\% energy & 100.0 & 14.6 & 29.0 & 56.4 \\
Control appetizer & & & & \\
White bread & 20.5 & 1.71 & 0.78 & 9.84 \\
Tomatoes & 10 & 0.07 & 0.01 & 0.33 \\
Pimentoes & 5 & 0.05 & 0.01 & 0.21 \\
Cream cheese (regular) & 10 & 1.07 & 1.67 & 0.40 \\
Total: g & 45.5 & 2.9 & 2.5 & 10.8 \\
$\quad$ kJ & 322.2 & 48.5 & 92.9 & 180.3 \\
$\quad \%$ energy & 100.0 & 15.1 & 28.9 & 56.0 \\
\hline
\end{tabular}

Table 4. Lists of foods served (in large amounts) during the lunch-time buffet

\begin{tabular}{lll}
\hline Turkey & Ketchup & Fudge \\
Salmon & White bread & Milk $(1 \%$ fat $)$ \\
Pâté & Crackers & Milk $(2 \%$ fat) \\
Ham & (Premium plus $\left.{ }^{\circledR}\right)$ & Milk $(3.25 \%$ fat) \\
Gruyère cheese & Lettuce & Orange juice \\
Mozzarella cheese & Tomatoes & Apple juice \\
Cottage cheese & Carrots & Cola \\
Butter & Oranges & 7-up ${ }^{\circledR}$ \\
Mayonnaise & Apples & Crisps \\
Vinegar & Tea biscuits & (Ruffles ${ }^{\circledR}$ rippled) \\
Mustard & Fruit yoghurt & Water \\
& &
\end{tabular}

Table 5. Lists of foods served (in large amounts) during the afternoon snack

\begin{tabular}{ll}
\hline Milk (2\% fat) & Chocolate cookies \\
Cola & Oreo $^{\circledR}$ cookies \\
7-up ${ }^{\circledR}$ & Crackers (Premium plus $^{\circledR}$ ) \\
Quaker Dipp Bars ${ }^{\circledR}$ & Ritz $^{\circledR}$ crackers \\
Crisps (Ruffles ${ }^{\circledR}$ rippled) & Tea biscuits \\
\hline
\end{tabular}

